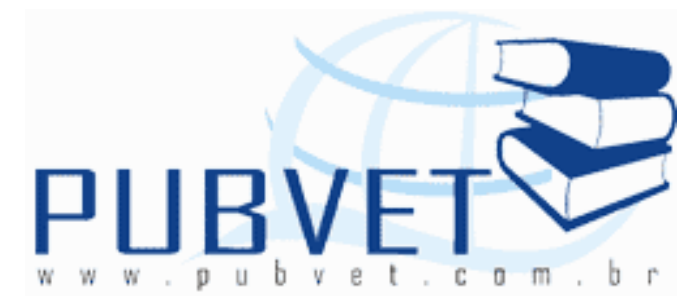

PUBVET, Publicações em Medicina Veterinária e Zootecnia.

\title{
Pesquisa de Dirofilaria immitis e Dipetalonema reconditum no canil municipal de Itajaí, Santa Catarina, Brasil
}

\footnotetext{
Raphael Nikolas Lira ${ }^{1}$, Marthin Raboch Lempek ${ }^{2}$, Camila de Castro Neves ${ }^{3}$, Júlio César de Souza Junior ${ }^{4}$, Germano Luiz Depinné Poffo ${ }^{1}$
}

${ }^{1}$ Médico Veterinário autônomo.

${ }^{2}$ Discente do curso de Medicina Veterinária, Universidade Estadual de Santa Catarina - UDESC, Lages, Santa Catarina, Brasil.

${ }^{3}$ Professora Doutora em Cirurgia Veterinária, FCAV - UNESP, Jaboticabal - SP.

${ }^{4}$ Docente do curso de Medicina Veterinária, Fundação Universidade Regional de Blumenau - FURB, Blumenau, Santa Catarina, Brasil.

*Endereço para correspondência: raphaelira@hotmail.com

\section{Resumo}

A dirofilariose é uma doença parasitária causada pelo filarídeo Dirofilaria immitis. É relatada em várias espécies sendo o cão a mais importante. Concentra-se principalmente em regiões litorâneas, e é considerada uma zoonose. A presente pesquisa tem como objetivo investigar a possível infecção por Dirofilaria immitis e Dipetalonema reconditum em cães mantidos no canil municipal de Itajaí, Santa Catarina, Brasil.

Palavras-chave: Dirofilariose, zoonose, cães. 


\title{
Research of Dirofilaria immitis and Dipetalonema reconditum in the Kennel of Itajaí, Santa Catarina, Brasil.
}

\begin{abstract}
The Dirofilariosis is a parasitic disease caused by a heartworm called Dirofilaria immitis. It Is reported in several species but the dog being the most important. Concentrated mainly in coastal regions, and is considered a zoonosis. This research aims to investigate the possible infection by Dirofilaria immitis and Dipetalonema reconditum in dogs kept in the kennel of Itajai, Santa Catarina, Brazil.
\end{abstract}

Keywords: Dirofilariosis, zoonosis, dogs.

\section{Introdução}

A dirofilariose é uma doença parasitária causada pelo filarídeo Dirofilaria immitis ( $D$. immitis), sendo relatada em várias espécies (gato, raposa, furão), inclusive o cão que é considerado o hospedeiro mais importante. É uma afecção de caráter cosmopolita e no Brasil as áreas de maior prevalência situam-se em regiões litorâneas tropicais e subtropicais principalmente por oferecer um ambiente propício para o desenvolvimento de vetores potenciais (LARBARTHE et al., 1998). Dipetalonema reconditum ( $D$. reconditum) é considerado o helminto causador da filariose assintomática em cães e gatos em várias regiões do Brasil podendo ocorrer infecções simultâneas com $D$. immitis (PATTON \& FAULKNER, 1992).

A dirofilariose é considerada uma zoonose pela Organização Mundial da Saúde (OMS), desde 1979. Nos seres humanos o parasito apenas se desenvolve até o estágio larval L4, sendo encontrado como nódulos pulmonares geralmente mimetizando neoplasias e levando ao diagnóstico errôneo. Esses pacientes geralmente são diagnosticados em exames radiográficos de rotina e podem se apresentar assintomáticos durante a consulta (CAVALLAZZI et al., 2002). 
A prevalência de dirofilariose canina em todo o Brasil foi assinalada ao redor de 9,2\% (GUERRERO et al. 1992). As áreas de maior prevalência situamse em regiões litorâneas tropicais e subtropicais (GERMANO et al. 1985; MEYER et al. 1994, LABARTHE, 1998).

O objetivo do presente trabalho foi investigar a possível infecção por Dirofilaria immitis e Dipetalonema reconditum em cães mantidos no canil municipal de Itajaí, Santa Catarina, Brasil. Além disso, identificar a proporção de cães infectados por $D$. immitis e $D$. reconditum, e a relação do parasitismo com o sexo dos animais.

\section{Materiais e Métodos}

A pesquisa foi realizada no canil municipal de Itajaí localizado no bairro Itaipava. É administrado pela Secretaria Municipal de Saúde e está sob a responsabilidade do Departamento de Vigilância Epidemiológica. Foram incluídos no estudo animais independentes de raça, com no mínimo seis meses de idade, machos e fêmeas de pesos e tamanhos variados, e mantidos no local. A idade foi determinada pela inspeção da dentição. A população do estudo é composta por 250 cães. Destes foram selecionados um $\mathrm{n}$ amostral de 137 animais, que obedeceram aos critérios de inclusão. A coleta de material biológico foi realizada no período da manhã e logo após as refeições.

Foi coletado aproximadamente $5 \mathrm{~mL}$ de sangue periférico, após prévia anti-sepsia do local com álcool iodado, sendo as respectivas amostras identificadas individualmente, acondicionadas em frascos contendo anticoagulante EDTA $(0,03 \mathrm{~mL}$ de Sal Sódico do Ácido Etilenodiaminotetracético), mantidas refrigeradas em caixa de isopor com gelo, e enviadas ao Laboratório de Parasitologia da Fundação Universidade Regional de Blumenau - FURB para posterior análise.

As análises laboratoriais foram realizadas por meio das técnicas de Gota espessa e Knott modificado por Newton \& Wright (1956). A leitura das lâminas foi realizada em duplicata para maior confiabilidade dos testes. Por motivos financeiros não foi possível à realização do teste imunológico ELISA ou 
Polimerase Chain Reaction (PCR). Para análise estatística foi utilizado o teste de Qui-quadrado para comparar a freqüência de microfilárias entre o sexo e idade dos animais infectados.

\section{Resultados e discussão}

De 137 cães analisados, foram encontradas 6 amostras positivas. No exame direto a fresco apenas 3 animais (2,19\%) apresentaram positividade para microfilárias. Já no teste de Knott modificado nenhum animal se apresentou positivo para Dirofilaria immitis, porém em todas as 6 amostras positivas foram confirmadas a presença de Dipetalonema reconditum, conferindo prevalência de 4,38\%. Resultados semelhantes foram relatados por Yai et al. (1991), que encontraram uma prevalência no município de São Paulo de $19,07 \%$ para $D$. reconditum e nenhuma para $D$. immitis. Em outro estudo realizado no município de Florianópolis também não houve casos positivos para D. immitis dos 138 animais avaliados (MACHADO, 2005).

Tabela 1. Prevalência das microfilárias encontradas nos exames Gota espessa e Knott modificado de acordo com idade e sexo.

\begin{tabular}{|c|c|c|c|c|c|}
\hline Fatores & $\begin{array}{c}\text { Gota } \\
\text { espessa }(n=3)\end{array}$ & $\begin{array}{c}\text { IC } \\
(95 \%)\end{array}$ & $\begin{array}{l}\text { Knott modificado } \\
\qquad(n=6)\end{array}$ & IC (95\%) & $\mathbf{P}$ \\
\hline \multicolumn{6}{|l|}{ Idade } \\
\hline Até 2 anos & -- & -- & $1(0,73 \%)$ & $(0 \%-2,2 \%)$ & -- \\
\hline $2-5$ anos & $3(2,19 \%)$ & $(0 \%-4,6 \%)$ & $4(2,92 \%)$ & $(0,1 \%-5,7 \%)$ & 0,7018 \\
\hline$>5$ anos & -- & -- & $1(0,73 \%)$ & $(0 \%-2,2 \%)$ & -- \\
\hline \multicolumn{6}{|l|}{ Sexo } \\
\hline Macho $(n=42)$ & $1(0,73 \%)$ & $(0 \%-2,2 \%)$ & $1(0,73 \%)$ & $(0 \%-2,2 \%)$ & -- \\
\hline Fêmea $(n=95)$ & $2(1,46 \%)$ & $(0 \%-3,5 \%)$ & $5(3,65 \%)$ & $(0,5 \%-6,8 \%)$ & 0,2507 \\
\hline TOTAL $(n=137)$ & $3(2,19 \%)$ & $(0 \%-4,6 \%)$ & $6(4,38 \%)$ & $(1 \%-7,8 \%)$ & 0,3092 \\
\hline
\end{tabular}

I - Comparando machos (1/42; $2,38 \%)$ e fêmeas $(5 / 95 ; 5,26 \%)(p=0,4472)$

II - Teste Qui-Quadrado (proporções independentes); considere diferenças significativas se $\mathrm{P}<0,05$.

III - Intervalo de confiança com nível de confiança de $95 \%$.

Dentre o total de cães no estudo, 95 (69,3 \%) eram fêmeas e $42(30,7$ \%) machos (Figura 1). O fato de a grande maioria amostral ser fêmea pode ter 
relação com a ausência de positividade, visto que estudos revelaram positividade maior em machos do que em fêmeas (MENDONÇA et al., 1994; SOUZA \& LARSSON, 2001). De acordo com Selby et al. (1980), machos inteiros apresentam maior risco de infecção provavelmente por serem utilizados para guarda, esporte e caça aumentando assim a probabilidade de contato com vetores potenciais.

Outro fator considerado foi a idade (Figura 1). Segundo resultados obtidos por Beugnet et al. (1994), e posteriormente por Almeida et al. (2001), a idade influencia na positividade dos animais sendo que quanto mais velho o animal maior a chance de o mesmo ser positivo para $D$. immitis, isso pode ter relação com o tempo de exposição do animal ao filarídeo, pois sabe-se que o mesmo leva pelo menos 6 meses para se alojar no ventrículo direito e o cão se tornar microfilarêmico. Já que a prevalência $D$. immitis aumenta progressivamente com a faixa etária, o que também pode ter influenciado nos resultados é que $81,02 \%$ dos cães tinham menos de quatro anos (Figura 1 ).

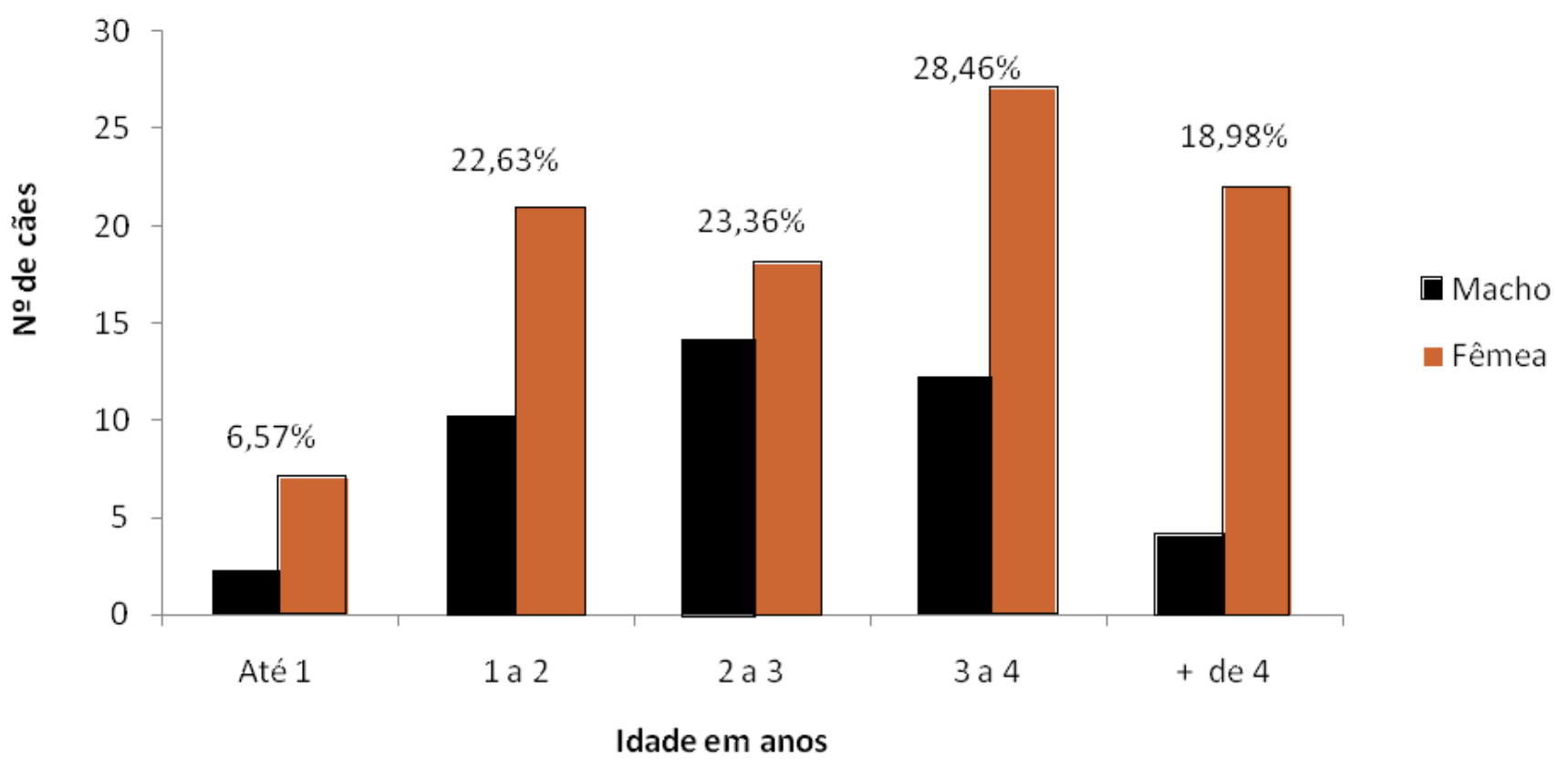

Figura 1. Idade e distribuição dos cães machos e fêmeas analisados na pesquisa de microfilárias, no Canil municipal de Itajaí, Santa Catarina, entre Agosto e Novembro de 2010. 
A colheita de sangue foi realizada logo após a refeição dos animais, pois de acordo com Ettinger \& Feldman (2004), a microfilaremia encontra-se elevada no período noturno e após a alimentação.

O presente estudo não revelou positividade para $D$. immitis, o que pode não estar demonstrando a realidade do canil, pois uma infecção oculta pode estar presente. Isso pode ocorrer quando há infecção unissexuada, existência somente de vermes imaturos (menos de 6 meses de infecção) e principalmente por medicações preventivas mensais (LOK et al., 1988). Destaca-se que a não realização do teste sorológico ELISA (Snap test) foi um fator limitante, pois se trata de um teste altamente sensível e específico (GARCEZ et al., 2006), e também capaz de diagnosticar a forma oculta da infecção (ROTH et al. 1993; McTIER et al., 1995).

Não foi encontrada diferença estatística significante quanto à prevalência de $D$. reconditum entre o sexo dos animais $(p=0,4472)$ (Tabela 1$)$.

\section{Conclusão}

Neste estudo, não se pôde comprovar a presença de infecção por $D$. immitis em cães mantidos no Canil Municipal de Itajaí. Porém, a forma oculta da doença pode estar presente em alguns animais, visto que se trata de uma região litorânea, e que recebe uma grande quantidade de turistas que possivelmente trazem seus animais.

Diante disso, entende-se que outras metodologias, como por exemplo, Polimerase Chain Reaction (PCR) ou pesquisa de antígenos (ELISA - Snap Test) são necessárias para investigar a possível infecção mista e/ou forma oculta da doença no canil.

\section{Referências Bibliográficas}

ALMEIDA, M.A.O.; BARROS, M.T.G.; SANTOS, E.P. et al. Parasitismo de cães por microfilárias de Dirofilaria immitis: influência da raça, sexo e idade. Revista Brasileira de Saúde e

Produção Animal, v.2, p. 59-64, 2001. 
BEUGNET, F.; ROUS, V.; LEUS, M. et al. Effect of age in cardiopulmonary canine dirofilariasis. Choice of date for commencement of chemoprophylaxis. Revue de Medecine Vetérinaire, Toulouse, v. 1, n. 145, p. 59-64, Jar. 1994.

CAVALLAZZI, R.S.; CAVALLAZI, A.C; SOUZA, V.I. et al. Dirofilariose pulmonar humana: relato de sete casos. J Pneumol., São Paulo, p. 100-102. mar./abril, 2002.

ETTINGER, J.S.; FELDMAN, C.E. Tratado de medicina interna veterinária. 5. ed. Rio de Janeiro: Guanabara koogan, 2004. v.1

GARCEZ L.M.; de SOUZA, N.F.; MOTA, E.F. et al. Focos de dirofilariose canina na Ilha de Marajó: um fator de risco para a saúde humana. Rev. Soc. Bras. Med. Trop. v. 39, n. 4, p. 333-336. jul./ago. 2006.

GERMANO, P.M.L.; ESHIZAKA, M.M.; ERBOLATO, E.B. Dirofiariose canina: caes e gatos. São Paulo, p. 16-21, 1985.

GUERRERO, J.; DUCOS de la HITE, J.; GENCHI, C. et al. Update on the distribuition of Dirofilaria immitis in dogs from Southern Europa and Latin America. In: PROCEEDINGS OF THE HEARTWORM SYMPOSIUM, 1992, Texas: American Hookworm Society, 1992. p. 31-37.

LABARTHE, N.V.; SERRÃO, M.L.; MELO, F.Y. et al. Natural potential vectors of Dirofilaria immitis (Leidy, 1856) in Itacoatiara, oceanic region of Niterói Municipality, Rio de Janeiro, Brazil. Mem. Inst. Oswaldo Cruz, Rio de Janeiro, v. 93, p. 425-432, 1998.

LABARTHE, N.V. Epidemiologia da Dirofilariose Canina na Baixada Litorânea Fluminense, Brasil. 1998. 101f. Tese (Doutorado em Ciências), Fund. Inst. Oswaldo Cruz - FIOCRUZ, Rio de Janeiro.

LOK, J. B.; HARPAZ, T.; KNIGHT, D. H. Abnormal patterns of embryogenesis in Dirofilaria immitis treated with ivermectin. J helminthol., London, v. 62, n. 3, p. 175-180, Sep. 1988.

MACHADO, E. S. Aspectos epidemiológicos de Dirofilariose Canina e Humana, no município de Florianópolis, Brasil. Perfil de uma zoonose. 2005. Tese (Mestrado em Saúde Pública), Universidade Federal de Santa Catarina - UFSC, Santa Catarina.

MENDONÇA, I.L.; CARVALHO, V.; SERRA-FREIRE, N.M. et al. Ocorrência de dirofilariose canina no Município de Teresina-Piaui. In: CONGRESSO BRASILEIRO MEDICINA VETERINÁRIA, 1994, Olinda. Anais... Olinda: SBMV, 1994. p.256.

MEYER, H.P.; WOLVEKAMP, P.; Van MAANEN, C. et al. Seven cases of heartworm disease (dirofilariosis) in dogs in the Netherlands. Vet. q., The Hague, v. 16, n. 3, p. 169-174. Oct. 1994.

MCTIER, T.L.; MCCALL, J.W.; SUPAKORNDEJ, N. Features of adult heartworm antigen test kits. In: Soll MD, Knight DH (eds): PROCEEDINGS OF THE HEARTWORM SYMPOSIUM, 1995, Auburn, Alabama. Batavia, IL, American Heartworm Society, 1995, p 115-120.

PATTON, S.; FAULKNER, C.T. Prevalence of Dirofilaria immitis and Dipetalonema reconditum infection in dogs: 805 cases (1980-1989). J. Am. Vet. Med. Assoc., Schaumburg, v. 200, n. 10, p. 1533-1534. May. 1992.

ROTH, L.; BROWN, L.; BRUM, S. et al. Comparison of three diagnostc tests for Dirofilaria immitis in a low-incidence area. J. vet. diag. invest., v.5, p.647-8, 1993. 
SOUZA, N.F.; LARSSON, M.H.M.A. Freqüência de dirofilariose canina (D. immitis) em algumas regiões do Estado de São Paulo por meio da detecção de antígenos circulantes. Arq. Bras.

Med. Vet. Zootec., v.53, p. 321-325, 2001.

SELBY, L.A.; CORWIN, R.M.; HAYES Jr, H.M. Risk factors associated with canine heartworm infection. Journal of American Veterinarian Medical Association. Schaumburg, v. 176, n. 1, p. 33-35, Jan. 1980.

YAI, L.E.O.; KASAI, N.; COSTA, M.J. et al. Prevalência de microfilárias em cães errantes capturados no município de São Paulo. Rev. Bras. Parasitol. Vet. São Paulo, v. 1, p. 74, 1991. 